\title{
Antimicrobial resistance in bacterial pathogens among hospitalised patients with severe invasive infections
}

\author{
OVIDIU ZLATIAN $^{1^{*}}$, ANDREI THEODOR BALASOIU ${ }^{2 *}$, MARIA BALASOIU $^{1 *}$, OANA CRISTEA $^{1}$, \\ ANCA OANA DOCEA ${ }^{3}$, RADU MITRUT ${ }^{4}$, DEMETRIOS A. SPANDIDOS ${ }^{5}$, ARISTIDES M. TSATSAKIS ${ }^{6}$, \\ GABRIELA BANCESCU $^{7}$ and DANIELA CALINA ${ }^{8}$ \\ Departments of ${ }^{1}$ Microbiology, ${ }^{2}$ Ophtalmology, ${ }^{3}$ Toxicology, and ${ }^{4}$ Pathology, \\ University of Medicine and Pharmacy of Craiova, 200349 Craiova, Romania; ${ }^{5}$ Laboratory of Clinical Virology, and \\ ${ }^{6}$ Laboratory of Toxicology, Medical School, University of Crete, 71003 Heraklion, Crete, Greece; \\ ${ }^{7}$ Department of Microbiology, University of Medicine and Pharmacy 'Carol Davila', 050474 Bucharest; \\ ${ }^{8}$ Department of Clinical Pharmacy, University of Medicine and Pharmacy of Craiova, 200349 Craiova, Romania
}

Received July 3, 2018; Accepted September 4, 2018

DOI: $10.3892 /$ etm.2018.6737

\begin{abstract}
The most severe infections are invasive infections, due to the fact that the germs can accumulate in multiple sites and produce a body-wide infection known as sepsis. Septic shock has the highest mortality rate among non-traumatic medical conditions. In this study, we aimed to evaluate the incidence and prevalence of invasive infections in a hospital environment. Another second objective was to establish the aetiology of invasive infections in our hospital and the antibiotic resistance profile of the germs involved, which are both important for determining the therapeutic approach for the treatment of these infections. The study included 505 hospitalized patients from which we collected a total of 974 blood cultures. For the analysis of the blood cultures, we used an automated incubator. The bottles flagged as positive were subcultured on blood agar, and the grown colonies were identified using an identification system. Invasive infections had a prevalence rate of $27.72 \%$ in our hospital. From the 974 blood cultures, we isolated 170 bacterial strains: Staphylococcus aureus (SA; 63 strains, $37.06 \%$ ), Klebsiella spp. (27 strains, 15.88\%), coagulase-negative staphylococci (CoNS; 18 strains, 10.59\%), Enterococcus spp. (17 strains, 10.00\%), Escherichia coli (12 strains, 7.06\%),
\end{abstract}

Correspondence to: Dr Anca Oana Docea, Department of Toxicology, University of Medicine and Pharmacy of Craiova, 2 Petru Rareş Street, 200349 Craiova, Romania

E-mail: ancadocea@gmail.com

Dr Daniela Calina, Department of Clinical Pharmacy, University of Medicine and Pharmacy of Craiova, 2 Petru Rareş Street, 200349 Craiova, Romania

E-mail: calinadaniela@gmail.com

*Contributed equally

Key words: severe invasive infections, blood cultures, bacterial strains, antimicrobial resistance, screening
Streptococcus spp. (11 strains, 6.47\%) and other bacterial species. The prevalence of methicillin-resistant SA (MRSA) in our study was $36.51 \%$ from the SA strains. The MRSA prevalence differed significantly according to age $(37.50 \%$ in adults vs. $28.57 \%$ in children, $\mathrm{P}=0.047)$ and ICU admission $(42.42 \%$ in ICU patients vs. $30.00 \%$ in non-ICU patients, $\mathrm{P}=0.018)$. We performed a multivariate analysis of the invasive infection risk which detected as significant predictors the admission into the cardiology ward and plastic surgery ward. On the whole, the findings of this study indicate that the high prevalence of Grampositive cocci in blood cultures, mostly SA, with multidrug resistance has important consequences for the management of invasive infections.

\section{Introduction}

Sepsis appears when an infection defeats the immune system, which IS usually able to fight against germs, and reaches the bloodstream. This term frequently used is septicaemia, which denotes a severe infection of the bloodstream.

Bacteraemia indicates the presence of bacteria in the blood. It is a medical emergency and that must be promptly controlled with appropriate antibiotics (1). Bacteraemia is a main cause of morbidity and mortality in hospitals, that can evolve into bloodstream infections (BSI). BSI are a major healthcare concern and are associated with a disease burden in hospitals comparable with myocardial infarction, major stroke and trauma, holding the 8th position in intra-hospital mortality causes (2). Bacteraemia can be classified according to the site of acquisition, either as community-onset or nosocomialacquired. Bacteraemia is of particular concern due to the high 30-day mortality rate of 16-29\% (3). Consequently, there are local and national surveillance programs that monitor the occurrence of bacteraemia in hospitals in an effort to improve prevention by empirical therapy and the control of invasive infections. Studies reporting data from hospital cohorts have described overall incidences, risk factors and mortality $(4,5)$; however, at least to the best of our knowledge, few studies to 
date have investigated the timing (daily incidence) of bacteraemia $(6,7)$.

Advances in medical pathogen detection technology and the demographic changes have altered the epidemiology of bacteraemia in recent decades, resulting in a shift in the pathogen spectrum. Although between the years 1987-2000, the aetiology of bacteraemia was dominated by Gram-positive bacteria, the prevalence of Gram-negative agents has increased and Escherichia coli has re-emerged as the most prevalent pathogen (8).

The major cause of morbidity and mortality worldwide is septicaemia and this type of infection can lead to longer periods of hospitalization and increased costs. It is estimated that the incidence rate of cases treated for sepsis in hospitals is 427 cases and that of cases of severe sepsis is 331 cases per 100,000 person-years (9).

The prevalent pathogen implicated in septicaemia is Staphylococcus aureus (SA). This bacterium can also lead to the development of infective endocarditis, as well as osteoarticular, skin and soft tissue infections, such as surgical site infections (10), pleuropulmonary manifestations (parapneumonic pleurisy) (11) and device-related infections (12). SA is implicated in $26 \%$ of cases of native endocarditis in adults, and the number of cases is increasing (13). This bacteria is often associated with severe fungal infections caused by fungi, such as Aspergillus or Fusarium (14). This clinical situation occurs particularly in immunosuppressed patients, or in patients with liver cirrhosis (15). With time, treatment becomes difficult due to the increased antibiotic resistance among the species isolated (16). As septicaemia is the most common bacterial infection, particularly in immunocompromised patients, it is important to determine the sensitivity and resistance of bacterial strains to antibiotics. Certain geographical variations in resistance have been described and in such cases, one must select the adequate antibiotic for each bacterium isolated (17). Blood cultures are essential for the diagnosis of BSI when there is a suspicion of severe focal infection that presents a risk of sepsis, as pyelonephritis, bronchopneumonia or infectious endocarditis. Blood cultures are also recommended for patients with severe septic syndrome, prolonged fever, prosthetic valves and metabolic disorders, such as diabetes.

The present study aimed to assess the epidemiology, aetiology, and temporal changes of bacteraemia episodes in patients from the County Clinical Emergency Hospital of Craiova, Romania, in an aim to determine the incidence and prevalence rates of these bacteria among patients with severe invasive infections.

\section{Materials and methods}

Study population. For the purpose of this study, from the hospital electronic database, we extracted all blood cultures collected between September 1, 2016 and July 31, 2017 from 505 patients (216 females and 289 males) hospitalized at the Clinical Emergency Hospital of Craiova, Romania. The patients were hospitalized in either the Intensive Care Unit (ICU; 272 patients), surgical wards (General Surgery, Plastic Surgery, Orthopaedic, Paediatric Surgery, Ophthalmology, Neurosurgery, Urology and Gynaecology wards; 47 patients), medical wards (Internal Medicine, Cardiology, Diabetes, Nephrology and Neurology wards, 129 patients), paediatric wards (45 patients) and oncological wards (12 patients). A total of 974 blood cultures were included in the study. The hospitalization time till the collection of the first blood culture was between 1 and 30 days, with a mean of 7.18 days.

A community-acquired (CA) bloodstream infection was defined as a positive blood culture in the first $48 \mathrm{~h}$ of admission, excluding re-admissions when the final discharge was $>48 \mathrm{~h}$. A hospital-acquired (HA) BSI was defined as a positive blood culture collected after at least $48 \mathrm{~h}$ from admission to the hospital, or within $48 \mathrm{~h}$ from the hospital discharge.

Microbiological methods. For collecting the blood cultures, we used specialized bottles provided together with the automated system Bactalert 3D ${ }^{\circledR}$ (bioMérieux SA, Marcy-l'Étoile, France), which contain the special formulation of culture media that allows the detection of both patients who did not receive antibiotic therapy and of those treated with antibiotics. For each patient, a set comprised of two culture bottles was collected, one for aerobic bacteria and one for anaerobic bacteria. The system incubated the bottles for up to 7 days and alerted the detection of growth. Immediately following the detection, the positive bottle was removed from the Bactalert 3D system and bacterial smears were examined following Gram staining which shows the shape of the bacteria (cocci or bacilli) and Gram grouping (Gram-positive and Gram-negative). According to the aspect indicated, the bacteria were inoculated on a Columbia blood agar plate, MacConkey and Sabouraud media (all from bioMérieux SA) with incubation at $37^{\circ} \mathrm{C}$ for $24 \mathrm{~h}$.

The identification of isolated microorganisms was performed using the system Vitek 2 Compact $^{\circledR}$ (bioMérieux SA) from the 24-h cultures on appropriate media based on the biochemical properties of bacteria assessed in specially designed cards with reagents that will change the colour after the enzymatic reaction. The cards are scanned every $15 \mathrm{~min}$ inside the system for colour change and once an identification is made, the card is ejected. The time for identification ranges from 4 to $14 \mathrm{~h}$. We used the identification cards, GP (for Gram-positive bacteria) and GN (for Gram-negative bacteria).

The Vitek 2 Compact ${ }^{\circledR}$ system was also used for antimicrobial susceptibility testing (AST), according to the guidelines of the current Clinical Laboratory Standards Institute (CLSI) (18), using the cards AST-N204 for Gram-negative bacteria of the genus Escherichia coli, Klebsiella spp. and Enterobacter spp., AST-N222 for Gram-negative glucose non-fermenters bacteria, AST-P592 for Gram-positive bacteria of the genus Staphylococcus spp., and AST-GP67 for Enterococcus spp., Streptococcus spp. and other Gram-positive bacteria. The base for automated bacterial antibiotic susceptibility is the antibiotic microdilution method: The bacterial strain is cultured in each of the cells from the card that contain various concentrations of antibiotics. Each cell is read 3 times once in $15 \mathrm{~min}$, and each reading uses 16 points to determine the absorbance of the cell, that is proportional with the concentration of bacteria. From these data for each strain, the minimum inhibitory concentration (MIC) for each antibiotic was determined, defined as the minimal concentration of antibiotic that stops bacterial growth in liquid culture.

Following the primary reading of the AST results, the software delivered with the Vitek 2 Compact $^{\circledR}$ analysed the 
resistance data using an advanced expert system (AES), that uses an exhaustive database of strains and MICs to validate the results and to interpret them, according to current CLSI guidelines. The final result includes both the MIC value obtained for each antibiotic and the interpretation as susceptible, intermediate resistant or resistant, that is of clinical value. Moreover, AES can classify the microorganisms in resistance phenotypes and detect the resistance mechanisms, as for example Extended Spectrum Beta-Lactamase (ESBLs) production.

Data and statistical analysis. The computerised hospital records of all eligible patients were retrieved and reviewed from the hospital electronic database, which contained clinical and laboratory data of all patients admitted to our hospital. The access to the database for the purpose of this study was approved by the Ethics Committee of Clinical County Emergency Hospital of Craiova, Romania. The patient specific data was depersonalised (e.g., names were not recorded, ages were approximated as greater or lower than 70 years). Candidate variables included demographic data, hospitalization time and diagnostics. Patients whose age was $<18$ years were considered children, and patients whose age was $>18$ years were considered adults.

Additionally, data related to blood culture, including the number of blood specimens used for culture, the number of positive cultures (if any), and the identification of all cultured isolates and their antimicrobial susceptibility, were also retrieved. The data were entered into STATA statistical software version 13.1 (StataCorp LP, College Station, TX, USA).

These patient groups were compared in terms of their demographic characteristics, underlying diseases, pathogens isolated and outcomes. The comparisons between the prevalence of infections in patient groups included the calculation of risk ratios and the significant difference between the groups was assessed using the Chi-squared test. In addition, the Chi-square test was used for the comparison of the prevalence of various pathogens in CA and HA invasive infections, or the prevalence of bacteraemia in groups defined by the presence or absence of the risk factors. The trend of increasing or decreasing prevalence with various infectious agents in consecutive months was tested using the Chi-square test for trend. The monthly relative prevalence rates were calculated in each month by dividing the number of patients with blood cultures positive for a certain bacteria by the number of patients with positive blood cultures in that month.

For the calculation of the risk of invasive infection and the mortality risk, and for the comparison of those between the groups we used Kaplan-Meyer survival analysis. The specialized procedures of STATA for survival analysis were used to calculate the incidence rates and the incidence rates ratio. Briefly, for each patient, we counted the number of days that patient remained in the hospital till the development of infection or death. All the days for all the patients were counted and then summed up. In a similar manner, the total number of patient/days that all patients spent in the hospital was calculated. The ratio between the two numbers is the incidence rate. The comparisons between patient groups defined by binary risk factors (e.g., diabetes) were performed using the log-rank test, which compares the equality of survivor functions in the 2 groups.
Following the initial Kaplan-Meyer survival analysis, we used a Cox regression model to quantify the effect of various risk factors on the risk of invasive infection and death, measured by the Hazard Ratio (HR). The performance of the Cox regression model was assessed by the calculation of sensitivity and specificity, followed by the construction of the receiver operator characteristic (ROC) curve and the calculation of the area under the curve (AUC) as the main measure of model fit and performance.

The multiple antibiotic resistance index (MAR) was calculated as the ratio between the number of resistant antibiotics and the total number of antibiotics tested for a given strain. The mean MARs in patients from different wards were compared by the analysis of variance (ANOVA) test, with the Bonferroni correction (19). When we had only 2 types of wards, as the patients were only from 2 different types of wards, we used the Student's t-test instead.

We calculated the average MAR per ward type by adding the MAR values for all patients hospitalised in wards belonging to a certain ward type and then divided by that the number of patients. We used multivariate logistic regression to analyse the risk factors for invasive infection or death, expressed as the odds ratio (OR). We used a logistic model with the dependent variable infection or death, in which we entered all the independent variables together: sex, age, ward type, diagnosis. Continuous data are expressed as the mean \pm standard deviation. All the statistical tests, comparisons and regression coefficients were considered significant if the probability to reject the null was $\mathrm{P}<0.05$.

\section{Results}

A total of 140 from the 505 patients analysed had positive blood cultures. In total, we collected 974 blood cultures, from which we isolated 170 bacterial strains. The prevalence rate of invasive bloodstream infections was 140/505, $27.72 \%$. The incidence rate of invasive infections was 5.75 per 100 patient-days. The incidence rate did not differ significantly between males and females $(\mathrm{P}=0.185)$ or between patients $<70$ years of age and those $>70$ years $(\mathrm{P}=0.491)$, but was significantly higher in patients with diabetes (incidence rate ratio, 1.49; $\mathrm{P}=0.072$ ) (Table $\mathrm{I}$ ). The time from admission until the collection of a positive blood culture varied between 0 and 30 days, with a mean of 5.27 days. A total of 26 patients of the $140(18.57 \%)$ had a positive blood culture in the first day, 42 patients $(30.00 \%)$ in the first 2 days and 62 patients $(44.28 \%)$ in the first 5 days. The hazard function from the survival analysis model revealed that the cumulative risk of infection was high in the first 2 days from admission, as these were patients with CA invasive infections. This then exhibited a decrease in day 3 and began to mildly increase beginning at day 4 . The invasive infections that are diagnosed from day 3 of hospitalization are considered HA and their risk increase proportionally with the number of days spent in the hospital. In this study, the infection risk remained steady beginning at day 14 of hospitalization (Fig. 1).

In total, 140 patients developed bacteraemia, 35 (25,00\%) in the first 2 days from admission, $88(62,85 \%)$ in the first seven days from admission and 132 (94,29\%) in the first 5 days. The incidence rate of death was 5.40 per 100 patient-days. The 
Table I. Incidence rates of the invasive infection and death broken down by risk factors.

\begin{tabular}{|c|c|c|c|c|c|c|}
\hline & \multicolumn{3}{|c|}{ Invasive infection risk } & \multicolumn{3}{|c|}{ Mortality risk } \\
\hline & $\begin{array}{c}\text { Incidence rate } \\
\text { (per } 100 \text { patient-days) }\end{array}$ & $\begin{array}{l}\text { Incidence } \\
\text { rate ratio }\end{array}$ & P-value ${ }^{a}$ & $\begin{array}{c}\text { Incidence rate } \\
\text { (per } 100 \text { patient-days) }\end{array}$ & $\begin{array}{l}\text { Incidence } \\
\text { rate ratio }\end{array}$ & P-value ${ }^{a}$ \\
\hline Global incidence rate & 5.75 & & & 5.40 & & \\
\hline \multicolumn{7}{|l|}{ Risk factor } \\
\hline \multicolumn{7}{|l|}{ Diabetes } \\
\hline Present & 6.81 & 1.49 & 0.072 & 3.19 & 0.49 & $0.028^{\mathrm{b}}$ \\
\hline Absent & 4.56 & & & 6.51 & & \\
\hline \multicolumn{7}{|l|}{ Sex } \\
\hline Female & 0.65 & 1.22 & 0.185 & 6.09 & 1.52 & 0.332 \\
\hline Male & 0.53 & & & 4.00 & & \\
\hline \multicolumn{7}{|l|}{ Age } \\
\hline$\geq 70$ years & 5.45 & 1.10 & 0.491 & 7.48 & 1.68 & $0.037^{\mathrm{b}}$ \\
\hline$<70$ years & 6.02 & & & 4.45 & & \\
\hline \multicolumn{7}{|l|}{ ICU admission } \\
\hline Yes & 6.31 & 0.96 & 0.798 & 7.57 & 4.88 & $<0.001^{\mathrm{b}}$ \\
\hline No & 6.56 & & & 1.55 & & \\
\hline
\end{tabular}

ICU, intensive care unit. ${ }^{a}$ The P-value was obtained from the log-rank test used to compare survivor functions in the 2 patient groups defined

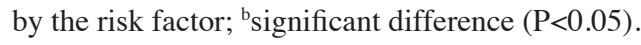

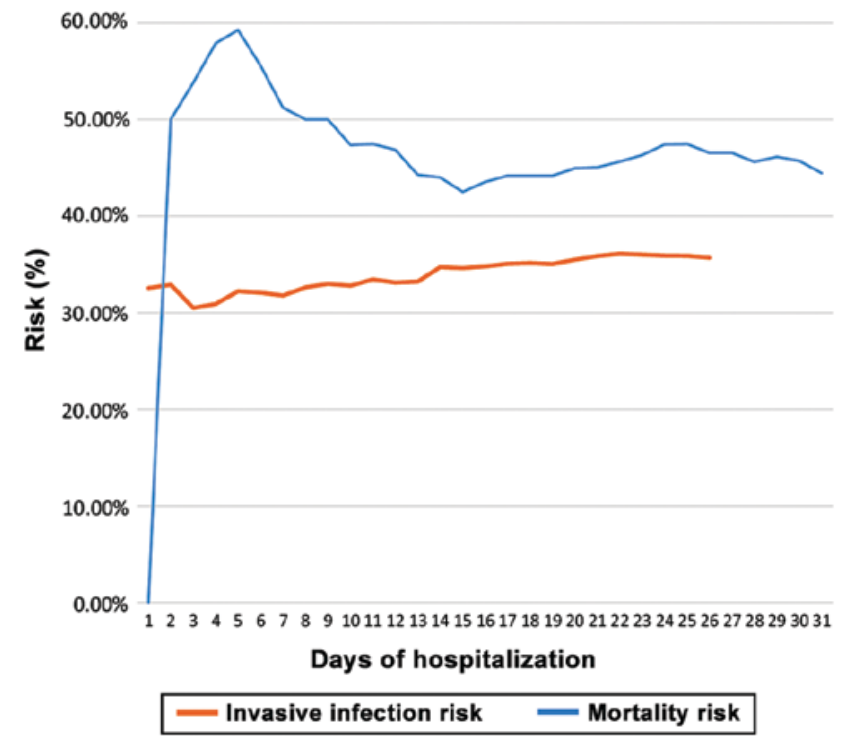

Figure 1. The risk of infection and mortality by the number of days passed from admission in the hospital.

infection risk was not markedly related with sex, age, admission to the ICU or diabetes. Nevertheless, The Kaplan-Meyer survival curves revealed a weak association of infection risk with age $\geq 70$ years and diabetes (Fig. 2).

In total, 21 patients of the $140(15.00 \%)$ died, $5(3.57 \%)$ in the first day, $7(5.00 \%)$ in the first 2 days and $15(10.71 \%)$ in the first 5 days. The death risk was significantly higher for patients aged $\geq 70$ years [incidence rate ratio (IRR), 1.68; $\mathrm{P}=0.037$ ] and for patients admitted to the ICU (IRR, 4.88; P<0.001), and lower for diabetic patients (IRR, 0.49; $\mathrm{P}=0.028$ ), but not for females vs. males $(\mathrm{P}=0.332)$ (Table $\mathrm{I})$. The Kaplan-Meyer survival curves revealed an association of 30 days mortality risk with age, admission to the ICU and diabetes (Fig. 3). The death risk was 0 in the first day, as none of the patients died on the day of admission. The death risk then increased over the first 5 days due to mortality associated with the cause of hospitalization and the rapid evolution of CA invasive infections. The majority of the patients for which blood cultures were collected during the first days of hospitalization were admitted for serious lifethreatening conditions, such as traffic accidents and other types of trauma injuries and fulminant endocarditis, that explain the high mortality risk during the first days from admission. After day 5, the death risk exhibited a marked decrease until day 15 , then it remained relatively steady till day 31 (Fig. 1). The survival analysis Cox regression model had a good fit, and the AUC was 0.8367 for the infection risk and 0.9096 for the mortality risk (Fig. 4).

We isolated 170 bacterial strains, and the most frequent were SA (63 strains, 37.06\%), Klebsiella spp. (27 strains, $15.88 \%$ ), coagulase-negative staphylococci (CoNS) that included Staphylococcus capitis, Staphylococcus hominis and Staphylococcus lungdunensis (18 strains, 10.59\%), Enterococcus spp. (17 strains, 10.00\%), Escherichia coli (12 strains, $7.06 \%$ ), Streptococcus spp., that included Streptococcus pneumoniae, Streptococcus agalactiae (11 strains, 6.47\%), non-fermenters such as Burkholderia cepacia (8 strains, $4.71 \%$ ), Acinetobacter baumannii (9 strains, 5,29\%) and other bacterial species (Table II).

SA strains had a prevalence of $6.67 \%$ in the medical wards, slightly lower than the prevalence of $9.23 \%$ in the surgical wards, but without statistical significance $(\mathrm{P}=0.478)$. The 

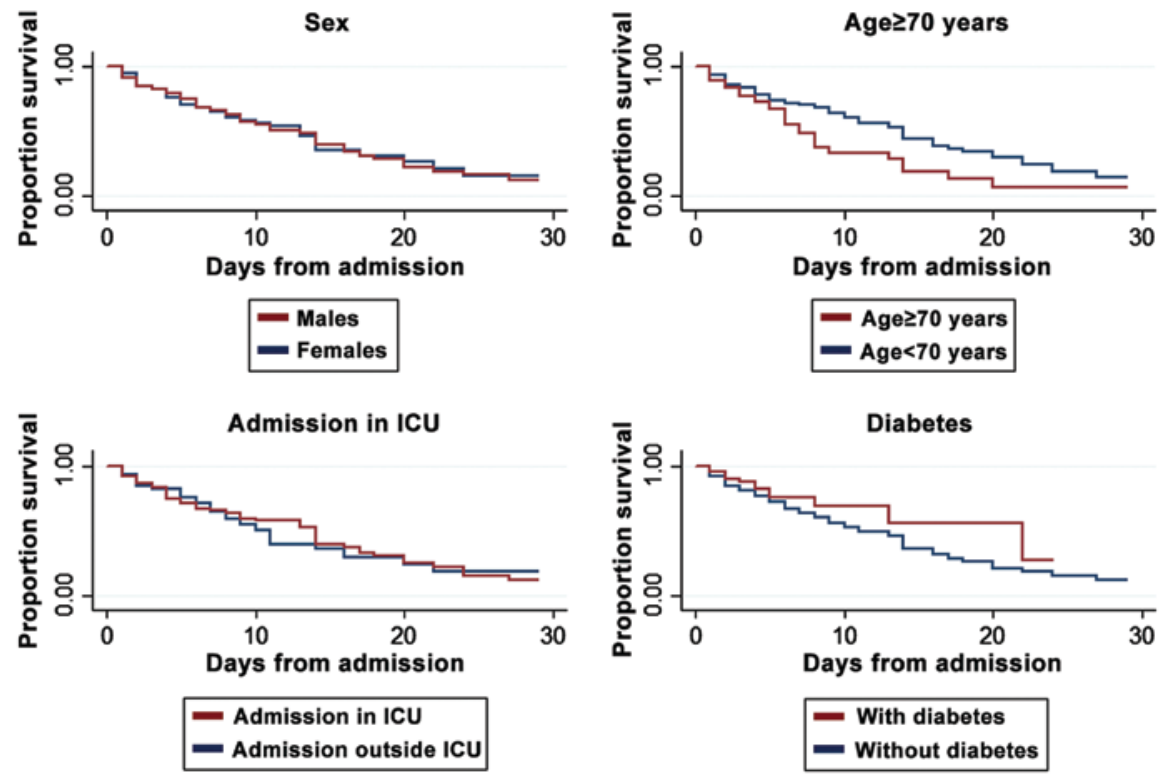

Figure 2. Kaplan-Meyer survival curves for invasive infections risk in relation with sex, age, intensive care unit (ICU) admission and diabetes.
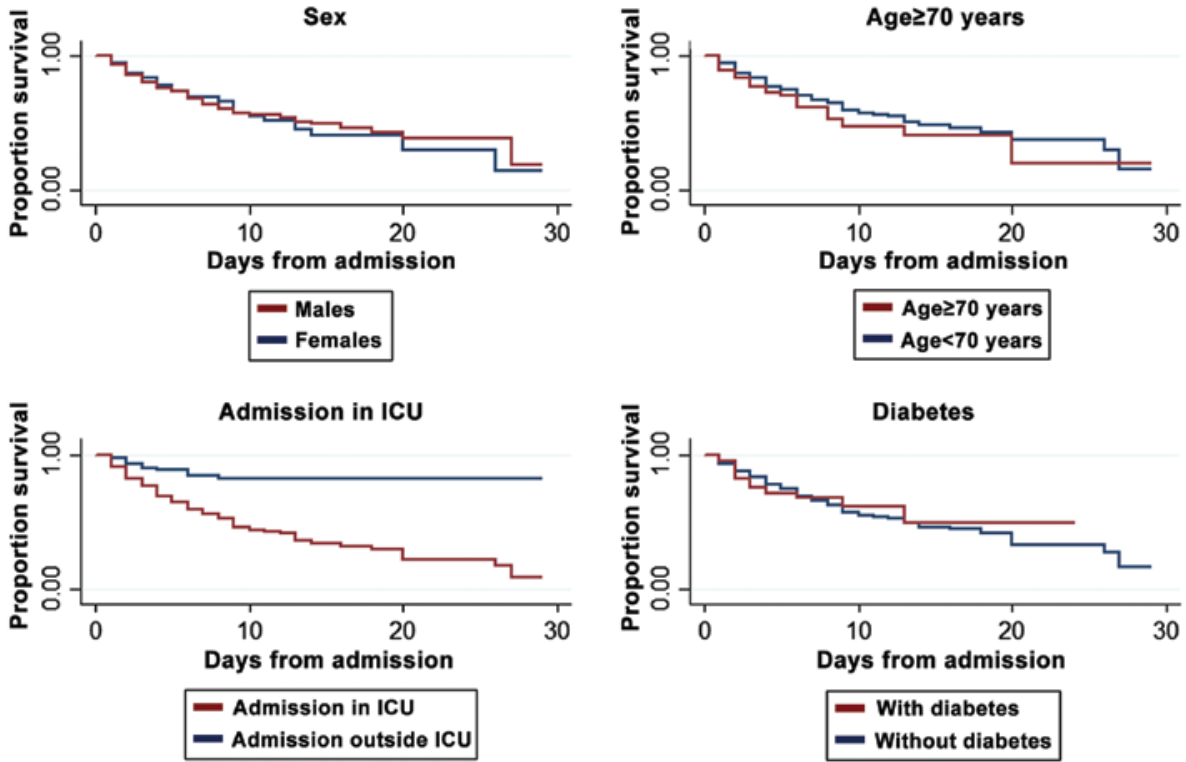

Figure 3. Kaplan-Meyer survival curves for 30 days mortality in relation to sex, age, intensive care unit (ICU) admission and diabetes.

prevalence of SA was slightly lower in the ICU (5.64\%) than in the other wards $(7.71 \%)$, but without reaching statistical significance $(\mathrm{P}=0.198)$. The prevalence of $\mathrm{SA}$ invasive infections did not differ significantly between adults and children $(\mathrm{P}=0.406)$, or between males and females $(\mathrm{P}=0.085)$ (Table III).

The methicillin-resistant SA (MRSA) prevalence in patients from our study was $36.51 \%$ from the SA strains or $2.36 \%$ from the total samples analysed. There were significant differences in MRSA prevalence between adults and children (37.50 vs. $28.57 \%, \mathrm{P}=0.047$ ) and between ICU and non-ICU patients (42.42 vs. $30.00 \%, \mathrm{P}=0.018$ ) (Table III).

The CA infections had a different aetiology compared with the HA infections. The number of HA infections with SA was more than double compared with the CA SA infections $(\mathrm{P}=0.049)$. The non-fermenters Gram-negative rods produced only HA infections ( $\mathrm{P}=0.006)$. The prevalence of CA and HA infections with Enterobacteriaceae and coagulase-negative staphylococci did not differ significantly (Fig. 5).

The relative prevalence of SA strains displayed a seasonal variation (Chi-square test for trend slope, 0.0121; $\mathrm{P}=0.006$ ) and the highest prevalence was recorded in May, 2017 (Fig. 6). The prevalence of infections with Enterobacteriaceae and coagulase negative staphylococci was generally under $10 \%$, without a clear trend (Fig. 6).

Using the associated medical conditions of the patients, we aimed to identify risk factors for invasive BSI. In this regard, we analysed neurological, cardiac and renal conditions, trauma, surgical procedures and various confirmed infection sites that may be the point of origin of sepsis. The positive blood culture rates differed by diagnosis, the highest rate being in the surgical 


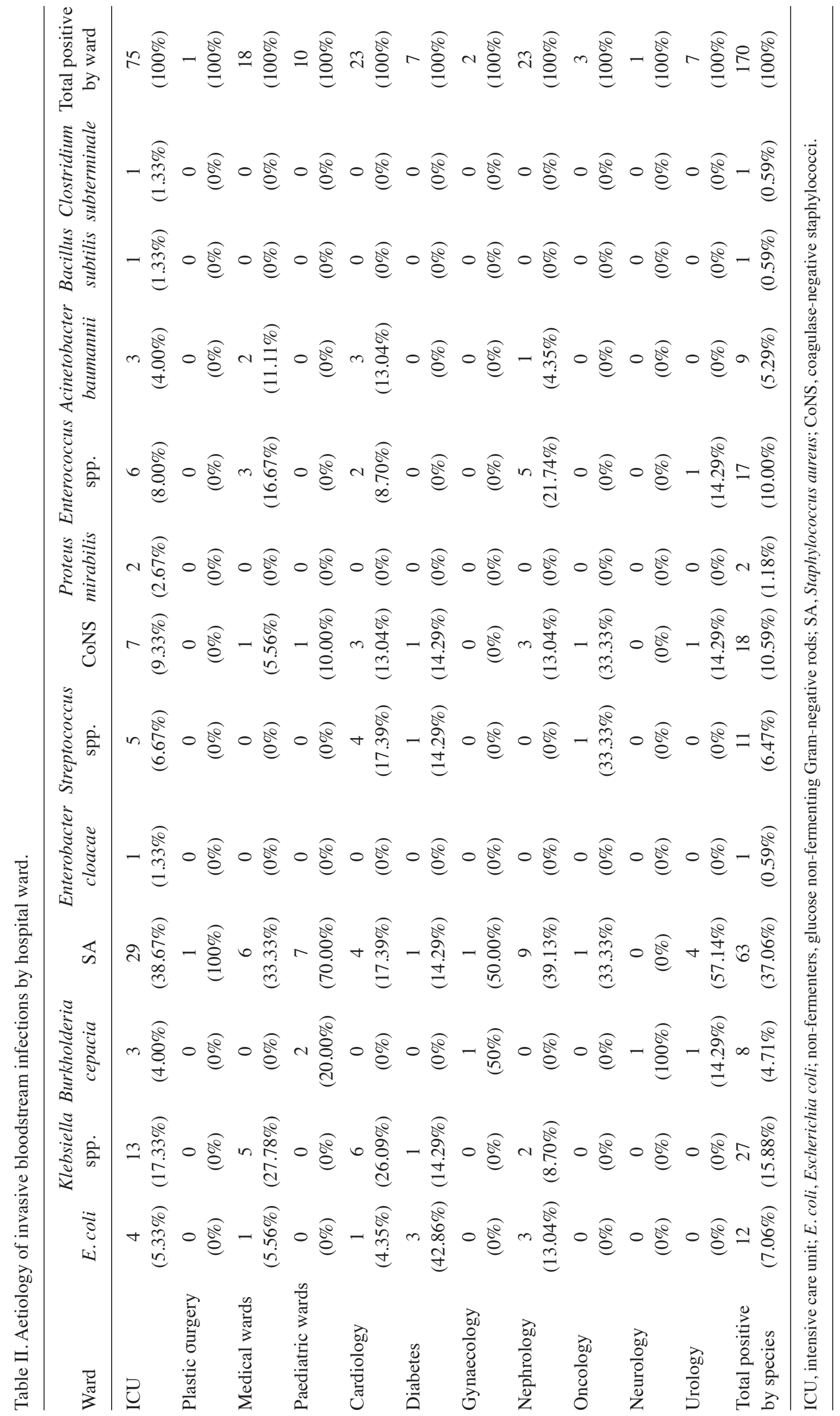


Table III. Prevalence rates of bacteraemia with Staphylococcus aureus and MRSA by age, hospitalization status (inpatient/outpatient), ward type and sex.

\begin{tabular}{|c|c|c|c|c|c|c|}
\hline \multirow[b]{2}{*}{ Variable/or risk factor } & \multicolumn{2}{|c|}{ S. aureus infection } & \multirow[b]{2}{*}{$\mathrm{P}$-value } & \multicolumn{2}{|c|}{ MRSA infection } & \multirow[b]{2}{*}{ P-value } \\
\hline & Positive & Negative & & Positive & Negative & \\
\hline All 974 samples & $63(6.47 \%)$ & $911(93.53 \%)$ & - & $23(36.51 / 2.36 \%)^{\mathrm{a}}$ & $951(62.49 / 97.64 \%)$ & - \\
\hline \multicolumn{7}{|l|}{ Sex } \\
\hline Male (548 samples) & $42(7.66 \%)$ & $506(92.34 \%)$ & 0.085 & $15(36.51 / 2.74 \%)^{\mathrm{a}}$ & $533(64.29 / 97.26 \%)$ & 0.853 \\
\hline Female (426 samples) & $21(4.93 \%)$ & $405(95.07 \%)$ & & $8(38.10 / 1.88 \%)^{\mathrm{a}}$ & $418(61.90 / 98.12 \%)$ & \\
\hline \multicolumn{7}{|l|}{ Age } \\
\hline Adults (893 samples) & $56(6.27 \%)$ & $837(93.73 \%)$ & 0.406 & $21(37.50 / 2.35 \%)^{\mathrm{a}}$ & $872(62.50 / 97.65 \%)^{\mathrm{a}}$ & $0.047^{\mathrm{b}}$ \\
\hline Children (81 samples) & $7(8.64 \%)$ & $74(91.36 \%)$ & & $2(28.57 / 2.47 \%)^{\mathrm{a}}$ & $79(71.43 / 97.53 \%)^{\mathrm{a}}$ & \\
\hline \multicolumn{7}{|l|}{ Type of ward } \\
\hline Medical (240 samples) & $16(6.67 \%)$ & $224(93.33 \%)$ & 0.478 & $5(31.25 / 1.88 \%)^{\mathrm{a}}$ & $235(68.75 / 98.12 \%)$ & 0.967 \\
\hline Surgical (65 samples) & $6(9.23 \%)$ & $59(90.77 \%)$ & & $2(33.33 / 3.08 \%)^{\mathrm{a}}$ & $63(66.67 / 96.92 \%)^{a}$ & \\
\hline \multicolumn{7}{|l|}{ ICU admission } \\
\hline ICU (585 samples) & $33(5.64 \%)$ & $552(94.36 \%)$ & 0.198 & $14(42.42 / 2.39 \%)^{\mathrm{a}}$ & $571(57.58 / 97.61 \%)^{\mathrm{a}}$ & $0.018^{\mathrm{b}}$ \\
\hline Non-ICU (389 samples) & $30(7.71 \%)$ & $359(92.29 \%)$ & & $9(30.00 / 2.31 \%)^{\mathrm{a}}$ & $380(70.00 / 97.69 \%)^{\mathrm{a}}$ & \\
\hline
\end{tabular}

The prevalence rates of infection with $S$. aureus and MRSA in groups defined by the risk factors were compared using the Chi-square test. MRSA, methicillin-resistant Staphylococcus aureus; ICU, intensive care unit. ${ }^{a}$ MRSA prevalence is expressed both as a ratio between MRSA strains Staphylococcus aureus strains and a ratio of MRSA strains from the total number of samples analysed. ${ }^{\mathrm{b}}$ Significant difference $(\mathrm{P}<0.05)$.
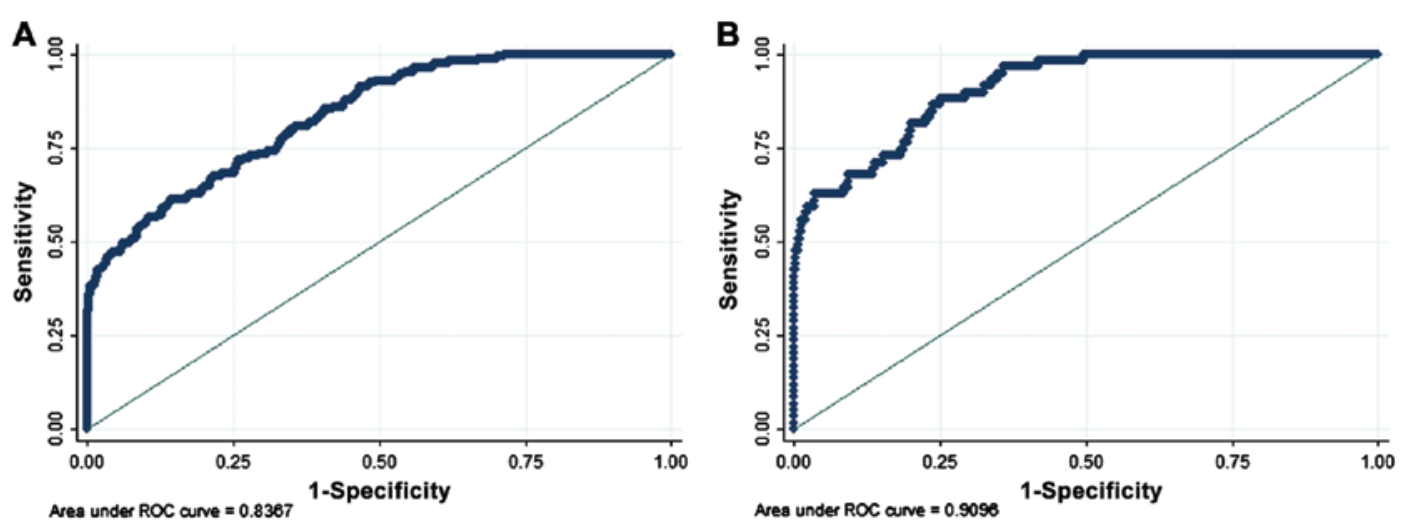

Figure 4. Receiver operator characteristic (ROC) analysis for the goodness-of-fit of the Cox regression survival model.

patients $(71.87 \%)$ and patients with central nervous system diseases $(55.84 \%)$. Lower rates (under 50\%) were recorded for patients with trauma, chronic kidney disease, cancer and other chronic diseases. The data are presented in Table IV. We found the greatest risk for invasive infections in patients subjected to surgery in the last 7 days [risk ratio (RR), 2.29; $\mathrm{P}<0.001$ ), who had neurological conditions $(\mathrm{RR}, 1.87$; $\mathrm{P}<0.0001)$ or who suffered from trauma (RR, 1.29; $\mathrm{P}<0.001)$.

As part of the survival analysis, we also performed a Cox proportional hazards regression which yielded the risk of infection associated with each risk factor (Table V) and also the risk of mortality in 30 days (Table VI). The most important risk factors for invasive infections were surgery in the prior 7 days (HR, 5.06; $\mathrm{P}<0.001)$, neurological conditions (HR, 4.29; $\mathrm{P}<0.001)$, chronic renal failure $(\mathrm{HR}, 3.43 ; \mathrm{P}<0.001)$, cardiac conditions $(\mathrm{HR}, 1.92 ; \mathrm{P}=0.002)$ and an age $>70$ years
(HR, 1.76, $\mathrm{P}=0.018$ ) (Table V). The most important risk factors for mortality were admission into the ICU (HR, 4.08; $\mathrm{P}<0.001$ ), neurological conditions ( $\mathrm{HR}, 4.05$; $\mathrm{P}<0.001)$, chronic renal failure $(\mathrm{HR}, 3.26 ; \mathrm{P}=0.003)$, surgery in the prior 7 days (HR, 2.95, $\mathrm{P}=0.011)$ and cancer $(\mathrm{HR}, 2.42 ; \mathrm{P}=0.032)$ (Table VI).

The multiple antibiotic resistance (MAR) index is an accurate measure of antibiotic resistance of a given strain. We calculated the mean MAR for each species, broken down by ward type. The data are presented in Table VII. There were significant differences in resistance between the wards only for Klebsiella spp., that had a higher resistance in the ICU compared with the medical wards $(\mathrm{P}=0.008)$, due to its high ability to acquire resistance plasmids by horizontal gene transfer and for SA that is easily acquired from the hospital environment and has a high capacity to modify the resistance profile during antibiotic treatment administered in the hospital. 
Table IV. The prevalence of bacteraemia in different clinical conditions.

\begin{tabular}{lccccc}
\hline Diagnostic & Samples & $\begin{array}{c}\text { Culture positive } \\
(\mathrm{n}=170)\end{array}$ & $\begin{array}{c}\text { Culture negative } \\
(\mathrm{n}=804)\end{array}$ & Risk ratio & P-value \\
\hline Neurological conditions & 77 & $43(55.84 \%)$ & $34(44.16 \%)$ & 1.87 & $<0.001^{\text {a }}$ \\
Cardiac conditions & 168 & $62(36.90 \%)$ & $106(63.10 \%)$ & 1.14 & 0.329 \\
Trauma & 35 & $15(42.86 \%)$ & $20(67.14 \%)$ & 1.29 & $<0.001^{\text {a }}$ \\
Chronic renal failure & 107 & $43(40.19 \%)$ & $64(59.81 \%)$ & 1.24 & 0.127 \\
Cancer & 39 & $15(38.46 \%)$ & $24(61.54 \%)$ & 1.14 & 0.542 \\
Chronic diseases & 105 & $34(32.38 \%)$ & $71(67.62 \%)$ & 0.94 & 0.688 \\
Surgery <7 days & 32 & $23(71.87 \%)$ & $9(28.13 \%)$ & 2.29 & $<0.001^{\text {a }}$ \\
\hline
\end{tabular}

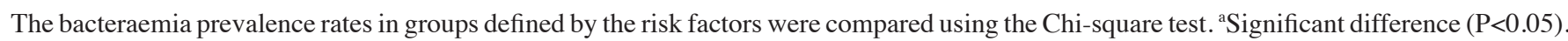

Table V. Proportional hazards Cox regression model of the risk factors for invasive infections.

\begin{tabular}{|c|c|c|c|c|c|c|}
\hline Risk factor & Hazard ratio & Std. Err. & $\mathrm{Z}$ & $\mathrm{P}>\mathrm{z}$ & \multicolumn{2}{|c|}{$95 \%$ CI } \\
\hline Female sex & 0.94 & 0.20 & -0.29 & 0.771 & 0.62 & 1.42 \\
\hline Age $\geq 70$ years & 1.76 & 0.42 & 2.37 & $0.018^{\mathrm{a}}$ & 1.10 & 2.82 \\
\hline Diabetes & 0.57 & 0.16 & -1.99 & $0.046^{\mathrm{a}}$ & 0.32 & 0.99 \\
\hline ICU admission & 1.02 & 0.20 & 0.12 & 0.907 & 0.70 & 1.50 \\
\hline Neurological conditions & 4.29 & 1.01 & 6.17 & $<0.001^{\mathrm{a}}$ & 2.70 & 6.82 \\
\hline Cardiac conditions & 1.92 & 0.40 & 3.09 & $0.002^{\mathrm{a}}$ & 1.27 & 2.90 \\
\hline Trauma & 1.11 & 0.37 & 0.31 & 0.758 & 0.58 & 2.12 \\
\hline Chronic renal failure & 3.43 & 1.03 & 4.11 & $<0.001^{\mathrm{a}}$ & 1.90 & 6.16 \\
\hline Cancer & 1.12 & 0.35 & 0.36 & 0.719 & 0.60 & 2.09 \\
\hline Other chronic diseases & 0.39 & 0.13 & -2.9 & $0.004^{\mathrm{a}}$ & 0.21 & 0.73 \\
\hline Surgery $<7$ days & 5.06 & 1.39 & 5.88 & $<0.001^{\mathrm{a}}$ & 2.95 & 8.68 \\
\hline
\end{tabular}

ICU, intensive care unit. a Statistically significant difference $(\mathrm{P}<0.05)$.

The resistance of SA was significantly higher in the ICU than in the medical wards $(\mathrm{P}=0.020)$.

The multivariate analysis of the risk of acquisition an invasive infection with any bacteria (Table VIII) demonstrated a significant effect of admission into the plastic surgery ward $(\mathrm{OR}=1.444, \mathrm{P}=0.082)$ and cardiology ward $(\mathrm{OR}, 2.313$; $\mathrm{P}=0.001)$.

The multivariate analysis of the risk of acquisition an invasive infection with MRSA (Table VIII) demonstrated a significant effect of the male sex $(\mathrm{OR}, 1.684 ; \mathrm{P}=0.080)$, an age $>50$ years $(\mathrm{OR}, 2.134 ; \mathrm{P}=0.050)$, admission into the ICU (OR, 1.518; $\mathrm{P}=0.058)$, plastic surgery ward (OR, 3.299; $\mathrm{P}=0.044)$, medical wards $(\mathrm{OR}, 0.278 ; \mathrm{P}=0.075)$ and cardiology (OR, 2.088; $\mathrm{P}=0.009)$.

\section{Discussion}

In our study, the highest prevalence of bacteraemia was found in patients subjected to recent surgery $(71.87 \%)$, which had an increased risk for acquisition of bacterial strains during or after surgery by inappropriate wound care. In neurological patients, the bacteraemia rate was also high due to prolonged immobilization, which is a risk factor for pulmonary or urinary tract infections, both with invasive potential. The bacteraemia prevalence was also relatively high in patients with chronic debilitating diseases (chronic renal failure and cancer) which lower the immunity that allows the invasion of blood by germs from various sites. The prevalence of invasive infections was also high in patients with neurological conditions $(53.52 \%)$, mostly stroke, patients that cannot move easily and have urinary catheters, so they have a high risk of developing lung and kidney infections that can reach the blood, on the background of lowered immunity due to hospital stay and lack of activity. We found that the most prevalent infectious agent was SA, similar with the study conducted by Ungureanu et al (20). Although there were minor differences between the prevalence of SA between patients admitted to the ICU and those admitted to other wards, the prevalence of MRSA was significantly higher in the ICU.

The low resistance rate of SA isolated from children is easily explained by the fact that these are mostly SA strains carried by the patient, usually in the nose or on the skin, and these strains were not exposed to long-term antibiotic treatments due to the low age of the patient. By contrast, the higher resistance of SA strains from adults can be explained by both 
Table VI. Proportional hazards Cox regression of the risk factors for 30 days mortality.

\begin{tabular}{|c|c|c|c|c|c|c|}
\hline Factor & Hazard ratio & Std. Err. & $\mathrm{Z}$ & $\mathrm{P}>\mathrm{z}$ & \multicolumn{2}{|c|}{$95 \%$ CI } \\
\hline Female sex & 1.32 & 0.38 & -0.98 & 0.328 & 0.430561 & 1.325547 \\
\hline Age $\geq 70$ years & 1.26 & 0.37 & 0.79 & 0.429 & 0.708051 & 2.253894 \\
\hline Diabetes & 0.38 & 0.23 & -1.60 & 0.109 & 0.115269 & 1.241342 \\
\hline ICU admission & 4.08 & 1.49 & 3.85 & $<0.001^{\mathrm{a}}$ & 1.993626 & 8.356247 \\
\hline Neurological conditions & 4.05 & 1.28 & 4.43 & $<0.001^{\mathrm{a}}$ & 2.179642 & 7.513619 \\
\hline Cardiac conditions & 1.13 & 0.37 & 0.38 & 0.705 & 0.599142 & 2.131884 \\
\hline Trauma & 1.24 & 0.59 & 0.46 & 0.646 & 0.491327 & 3.146228 \\
\hline Chronic renal failure & 3.26 & 1.30 & 2.96 & $0.003^{\mathrm{a}}$ & 1.491949 & 7.136156 \\
\hline Cancer & 2.42 & 0.99 & 2.15 & $0.032^{\mathrm{a}}$ & 1.079461 & 5.408272 \\
\hline Other chronic diseases & 0.29 & 0.15 & -2.41 & $0.016^{\mathrm{a}}$ & 0.104955 & 0.791273 \\
\hline Surgery $<7$ days & 2.95 & 1.26 & 2.53 & $0.011^{\mathrm{a}}$ & 1.27457 & 6.811629 \\
\hline
\end{tabular}

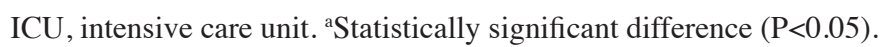

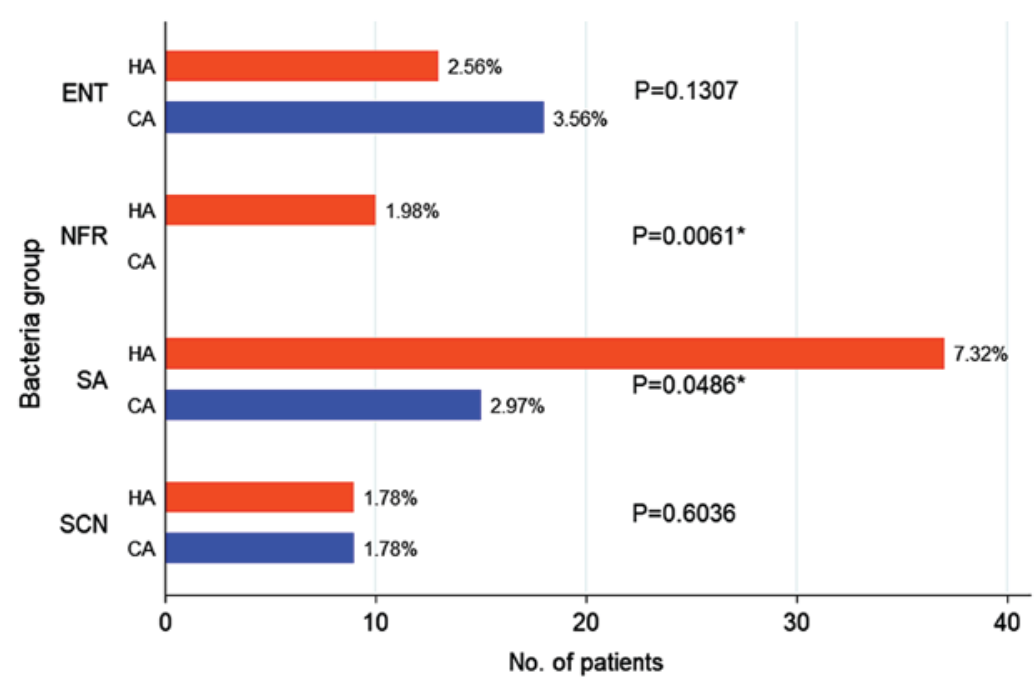

Figure 5. The prevalence of community versus hospital acquired bloodstream infections for different bacterial families. The prevalence was calculated as the number of patients infected divided by the total number of patients. The differences between prevalence rates were assessed using the Chi-square test. The asterisk $(*)$ indicates statistical significance $(\mathrm{P}<0.05)$.

the higher resistance of a patient's own SA strain, but also by the increased chance to acquire multi-resistant hospital SA strains, particularly in the ICU. In general, patients admitted to the ICU receive more antibiotics than other patients, which induces the development of multi-resistant strains.

In addition, CoNS are usually saprophytic bacteria in a patient's microbiota; thus, they do not have a high antibiotic resistance that explains the minor differences observed in the MAR between the wards. The lower MAR of SA in the medical wards compared with the ICU can be explained by the lower exposure to antibiotics, and the low MAR of CoNS in the paediatric wards is easily explained by the overall low exposure time of children to antibiotics, due to the low age $(21,22)$.

In a cross-sectional study carried out on two neonatal intensive care units in the Republic of Georgia, it was shown that the number of cases with confirmed bacteraemia was $126(63 \%)$ and from these, the most prevalent was Klebsiella pneumoniae, accounting for 36 (29\%) of positive isolates, followed by Enterobacter cloacae $(19,15 \%)$ and SA $(15,12 \%)(23)$. In our study, in the paediatric wards, the aetiology of blood cultures was as follows: From the 10 isolates, 7 were represented by SA (70\%), 2 non-fermenters bacilli (20\%) and one CoNS (10\%) (Table II).

The increase in bacteraemia with SA is significantly associated with the increasing numbers of admissions to hospitals, as observed in a study from Denmark over a 30-year period (24). Even if MRSA is responsible for the majority of bacteraemia cases with SA, compared with methicillin-sensitive SA, over the past decade, the incidence of bacteraemia with SA is decreasing (12). Such a tendency was also observed in our study, where the MRSA prevalence was $36.51 \%$ from the SA strains, but only $2.36 \%$ from the total samples analysed (Table III). MRSA infection is associated with poorer clinical outcomes (25).

In our study we also isolated strains of Proteus spp., Bacillus subtilis and Clostridium subterminale. These are 
Table VII. The multiple antibiotic resistance index (MAR) of isolated bacterial species, broken down by ward type.

\begin{tabular}{|c|c|c|c|c|c|c|c|}
\hline Bacterial species & $\begin{array}{c}\text { All } \\
\text { wards }\end{array}$ & $\begin{array}{c}\text { ICU } \\
(2 \text { wards })\end{array}$ & $\begin{array}{c}\text { Surgical } \\
(12 \text { wards }) \\
\left(\mathrm{P}-\text { value }^{\mathrm{a}}\right)\end{array}$ & $\begin{array}{l}\text { Medical } \\
\text { (6 wards) }\end{array}$ & $\begin{array}{l}\text { Paediatric } \\
(2 \text { wards })\end{array}$ & $\begin{array}{l}\text { Oncologic } \\
(2 \text { wards })\end{array}$ & P-value ${ }^{b}$ \\
\hline E. coli & $28.90 \pm 15.99 \%$ & $26.77 \pm 19.70 \%$ & - & $\begin{array}{c}30.43 \pm 14.27 \% \\
(1.000)\end{array}$ & - & - & 0.7156 \\
\hline Klebsiella spp. & $53.87 \pm 27.13 \%$ & $63.68 \pm 23.48 \%$ & - & $\begin{array}{c}30.58 \pm 20.89 \% \\
(0.008)\end{array}$ & - & - & $0.0020^{\mathrm{c}}$ \\
\hline $\begin{array}{l}\text { Burkholderia } \\
\text { cepacia }\end{array}$ & $72.22 \pm 28.79 \%$ & $78.57 \pm 22.85 \%$ & $\begin{array}{c}47.62 \pm 53.87 \% \\
(1.000)\end{array}$ & $\begin{array}{c}94.44 \pm 0.00 \% \\
(1.000)\end{array}$ & $\begin{array}{c}76.19 \pm 0.00 \% \\
(1.000)\end{array}$ & - & 0.6344 \\
\hline SA & $52.83 \pm 20.67 \%$ & $58.03 \pm 17.38 \%$ & $\begin{array}{c}57.91 \pm 19.29 \% \\
(0.898)\end{array}$ & $\begin{array}{c}49.70 \pm 23.87 \% \\
(0.020)^{\mathrm{d}}\end{array}$ & $\begin{array}{c}33.53 \pm 17.48 \% \\
(1.000)\end{array}$ & $\begin{array}{c}35.71 \pm 0.00 \% \\
\quad(1.000)\end{array}$ & $0.0405^{\mathrm{c}}$ \\
\hline $\begin{array}{l}\text { Enterobacter } \\
\text { cloacae }\end{array}$ & $78.94 \pm 0.00 \%$ & $78.94 \pm 0.00 \%$ & - & - & - & - & - \\
\hline Streptococcus spp. & $26.11 \pm 25.82 \%$ & $24.96 \pm 27.58 \%$ & - & $\begin{array}{c}21.43 \pm 0.00 \% \\
\quad(1.000)\end{array}$ & - & $\begin{array}{c}40.00 \pm 0.00 \% \\
(1.000)\end{array}$ & 0.8649 \\
\hline CoNS & $38.20+18.69 \%$ & $40.36 \pm 14.89 \%$ & $\begin{array}{c}28.57 \pm 0.00 \% \\
(1.000)\end{array}$ & $\begin{array}{c}36.11 \pm 25.58 \% \\
(1.000)\end{array}$ & $\begin{array}{c}13.33 \pm 0.00 \% \\
(1.000)\end{array}$ & $\begin{array}{c}61.54 \pm 0.00 \% \\
(1.000)\end{array}$ & 0.4752 \\
\hline Proteus mirabilis & $70.09 \pm 0.00 \%$ & $70.09 \pm 0.00 \%$ & - & - & - & - & - \\
\hline Enterococcus spp. & $70.07 \pm 19.36 \%$ & $69.32 \pm 23.23 \%$ & $\begin{array}{c}80.00 \pm 0.00 \% \\
(1.000)\end{array}$ & $\begin{array}{c}69.58 \pm 17.38 \% \\
(1.000)\end{array}$ & - & - & 0.8837 \\
\hline $\begin{array}{l}\text { Acinetobacter } \\
\text { baumannii }\end{array}$ & $79.39 \pm 9.30 \%$ & $77.19 \pm 10.64 \%$ & - & $\begin{array}{c}83.79 \pm 4.41 \% \\
(1.000)\end{array}$ & & - & \\
\hline Bacillus subtilis & $27.78 \pm 0.00 \%$ & $27.78 \pm 0.00 \%$ & - & - & - & - & - \\
\hline $\begin{array}{l}\text { Clostridium } \\
\text { Subterminale }\end{array}$ & $0.00 \pm 0.00 \%$ & $0.00 \pm 0.00 \%$ & - & - & - & - & - \\
\hline
\end{tabular}

MAR is shown as mean \pm standard deviation. The P-values in parentheses are from post-hoc tests with Bonferroni correction. ICU, intensive care unit; E. coli, Escherichia coli; non-fermenters, glucose non-fermenting Gram-negative rods; SA, Staphylococcus aureus; CoNS, coagulase-negative staphylococci. ${ }^{\mathrm{P}} \mathrm{P}$-value was computed by ANOVA test; ${ }^{\mathrm{b}} \mathrm{P}$-value was computed by the post-hoc tests after ANOVA with the Bonferroni correction. ${ }^{\mathrm{c}, \mathrm{d}}$ statistical significance $(\mathrm{P}<0.05)$.

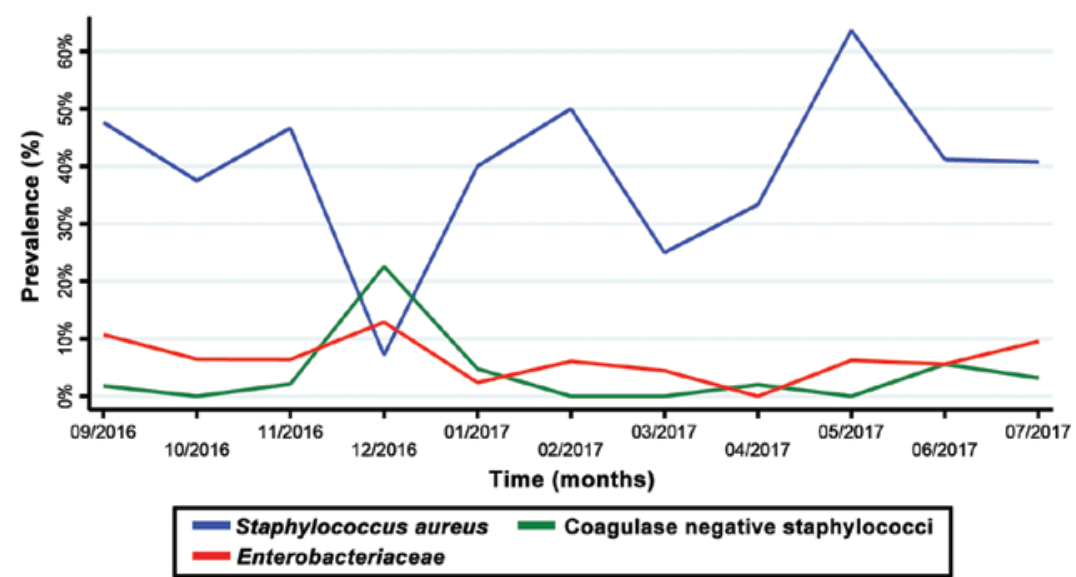

Figure 6. The seasonal variation of Staphylococcus aureus, coagulase-negative staphylococci and Enterobacteriaceae monthly relative prevalence. The monthly relative prevalence rates were calculated by dividing the number of patients infected with a certain bacteria by the number of patients infected with any bacteria in the given month.

considered contaminants of blood cultures and therefore we will not discuss there resistance.
The significant effect of admission into the cardiology unit $(\mathrm{OR}, 2.088 ; \mathrm{P}=0.009)$ on the risk of acquisition of invasive 
Table VIII. Results of the multivariate logistic regression analysis on the risk of invasive infection with any bacteria and in particular with MRSA.

\begin{tabular}{|c|c|c|c|c|}
\hline \multirow[b]{2}{*}{ Risk factor } & \multicolumn{2}{|c|}{ Any invasive infection } & \multicolumn{2}{|c|}{ Invasive infection with MRSA } \\
\hline & Odds ratio $(95 \% \mathrm{CI})$ & $\mathrm{P}$-value & Odds ratio $(95 \% \mathrm{CI})$ & $\mathrm{P}$-value \\
\hline Male sex & $0.681(0.42-0.99)$ & 0.075 & $1.684(0.98-2.52)$ & $0.080^{\mathrm{a}}$ \\
\hline Age $>50$ years & $1.003(0.63-1.78)$ & 0.989 & $2.134(0.99-5.73)$ & $0.055^{\mathrm{a}}$ \\
\hline \multicolumn{5}{|l|}{ Ward type } \\
\hline $\mathrm{ICU}$ & $0.687(0.25-2.36)$ & 0.487 & $1.518(0.96-3.02)$ & $0.058^{\mathrm{a}}$ \\
\hline Plastic surgery & $1.444(0.98-1.98)$ & $0.082^{\mathrm{a}}$ & $3.299(1.53-5.99)$ & $0.044^{\mathrm{a}}$ \\
\hline Medical wards & $1.134(1.01-4.69)$ & 0.833 & $0.278(0.12-1.06)$ & $0.075^{\mathrm{a}}$ \\
\hline Paediatric wards & $0.902(0.24-3.57)$ & 0.875 & $0.805(0.33-1.88)$ & 0.774 \\
\hline Cardiology & $2.313(0.26-3.94)$ & $0.001^{\mathrm{a}}$ & $2.088(1.34-5.65)$ & $0.009^{\mathrm{a}}$ \\
\hline Diabetes & $0.839(0.18-3.16)$ & 0.806 & $0.153(0.06-1.83)$ & 0.103 \\
\hline Gynaecology & $0.346(0.06-2.63)$ & 0.257 & $0.704(0.25-2.34)$ & 0.772 \\
\hline Nephrology & $1.265(0.32-4.56)$ & 0.711 & $0.528(0.02-2.21)$ & 0.348 \\
\hline Oncology & $0.462(0.13-3.87)$ & 0.377 & $0.431(0.11-4.32)$ & 0.467 \\
\hline Neurology & $0.1616(0.01-3.01)$ & 0.195 & - & - \\
\hline \multicolumn{5}{|l|}{ Diagnosis } \\
\hline Neurological conditions & $4.543(2.33-6.77)$ & $<0.001^{\mathrm{a}}$ & - & - \\
\hline Heart conditions & $1.446(0.45-3.02)$ & 0.163 & - & - \\
\hline Trauma & $2.146(0.95-3.01)$ & 0.088 & - & - \\
\hline Renal conditions & $1.492(0.55-2.42)$ & 0.236 & - & - \\
\hline Neoplasms & $2.117(0.99-5.66)$ & 0.054 & - & - \\
\hline Chronic conditions & $0.724(0.44-3.33)$ & 0.378 & - & - \\
\hline Constant & $0.672(0.42-0.70)$ & $<0.001$ & $0.070(0.02-0.11)$ & 0.001 \\
\hline Area under the ROC curve & \multicolumn{2}{|c|}{0.8367} & \multicolumn{2}{|c|}{0.9096} \\
\hline
\end{tabular}

${ }^{\text {a }}$ Statistically significant difference $(\mathrm{P}<0.10)$.

infection with any bacteria and with MRSA is easily explained by the selection bias due to the fact that patients suspected of infectious endocarditis or myocarditis are admitted into the cardiology ward.

This study had certain limitations. The most important limitation is the selection bias, as the study used as negative controls people for which the physician ordered a blood culture, which farther turned out to be negative. So the patients were already at risk for invasive infections.

Although blood cultures are an important component of diagnostic practice for antibiotic management in patients with pneumonia, several studies have questioned whether they should be performed $(26,27)$. The objective of this study was to evaluate the predictive factors of bacteraemia and the role of blood cultures in patients with community-onset pneumonia (community-acquired pneumonia and healthcare-associated pneumonia). Sometimes, patients with septicaemia are treated with antibiotics prior to the collection of the blood cultures and after the isolation and identification of the pathogen they will receive the proper treatment after the antibiogram results become

In conclusion, invasive infections are most commonly caused by SA, a bacteria with resistance to multiple antibiotics. This study identified key risk factors for invasive infections, which may be addressed with therapy adjustments in high-risk patients in order to reduce the incidence of invasive infections in hospitals. In the light of these results, pharmacotherapeutic management is difficult, and antibiotics administered require a correct diagnosis and antibiogram.

\section{Acknowledgements}

Not applicable.

\section{Funding}

No funding received.

\section{Availability of data and materials}

All data generated or analysed during the current study are included in this published article or are available from the corresponding author upon reasonable request.

\section{Authors' contributions}

All the authors were involved in conceiving and designing the study. OZ, MB and OC contributed to sample collection and 
intellectual input. OZ, MB, OC performed the experiments. OC, ATB, GB and RM collected the data, OZ, MB, DC, performed the statistical analysis. OZ, DC, AOD, ATB and RM drafted and wrote the manuscript. DC, AOD, DAS and AMT gave advice on the experimental design, interpreted the results and critically revised the manuscript. All authors have read and approved the final version of the manuscript.

\section{Ethics approval and consent to participate}

The access of the database for the purpose of this study was approved by the Ethics Committee of Clinical County Emergency Hospital of Craiova, Romania. Because we are a teaching hospital, all patients admitted in our hospital signed a written consent by which they agree that there medical data can be used in scientific studies.

\section{Patient consent for publication}

Not applicable.

\section{Competing interests}

DAS is the Editor-in-Chief for the journal, but had no personal involvement in the reviewing process, or any influence in terms of adjudicating on the final decision, for this article.

\section{References}

1. Kaspersen ER, Ræder J and Dahl V: Guidelines for treatment of sepsis. Tidsskr Nor Laegeforen 138: 2018.

2. Wenzel RP and Edmond MB: The impact of hospital-acquired bloodstream infections. Emerg Infect Dis 7: 174-177, 2001.

3. Nielsen SL, Lassen AT, Kolmos HJ, Jensen TG, Gradel KO and Pedersen C: The daily risk of bacteremia during hospitalization and associated 30-day mortality evaluated in relation to the traditional classification of bacteremia. Am J Infect Control 44: 167-172, 2016.

4. Anderson DJ, Moehring RW, Sloane R, Schmader KE, Weber DJ, Fowler VG Jr, Smathers E and Sexton DJ: Bloodstream infections in community hospitals in the 21st century: A multicenter cohort study. PLoS One 9: e91713, 2014.

5. Thaden JT, Park LP, Maskarinec SA, Ruffin F, Fowler VG Jr and van Duin D: Results from a 13-year prospective cohort study showincreased mortality associated with bloodstream infections caused by Pseudomonas aeruginosa compared to other bacteria Antimicrob Agents Chemother 61: e02671-e16, 2017.

6. Gradel KO, Nielsen SL, Pedersen C, Knudsen JD, Østergaard C, Arpi M, Jensen TG, Kolmos HJ, Schønheyder HC, Søgaard M, et al; Danish Collaborative Bacteraemia Network; Danish Observational Registry of Infectious Syndromes: No specific time window distinguishes between community-, healthcare-, and hospital-acquired bacteremia, but they are prognostically robust. Infect Control Hosp Epidemiol 35: 1474-1482, 2014.

7. Leibovici L, Schønheyder H, Pitlik SD, Samra Z and Møller JK: Bacteraemia caused by hospital-type micro-organisms during hospital stay. J Hosp Infect 44: 31-36, 2000.

8. Buetti N, Marschall J, Atkinson A and Kronenberg A; Swiss Centre for Antibiotic Resistance (ANRESIS): National Bloodstream Infection Surveillance in Switzerland 2008-2014: Different Patterns and Trends for University and Community Hospitals. Infect Control Hosp Epidemiol 37: 1060-1067, 2016.

9. Fleischmann C, Scherag A, Adhikari NK, Hartog CS, Tsaganos T, Schlattmann P, Angus DC and Reinhart K; International forum of acute care trialists: Assessment of global incidence and mortality of hospital-treated sepsis. Current Estimates and Limitations. Am J Respir Crit Care Med 193: 259-272, 2016.
10. Călina D, Docea AO, Rosu L, Zlatian O, Rosu AF, Anghelina F, Rogoveanu O, Arsene AL, Nicolae AC, Drăgoi CM, et al: Antimicrobial resistance development following surgical site infections. Mol Med Rep 15: 681-688, 2017.

11. Călina D, Roșu L, Roșu AF, Ianoşi G, Ianoşi S, Zlatian O, Mitruț R, Docea AO, Rogoveanu O, Mitruț P, et al: Etiological diagnosis and pharmacotherapeutic management of parapneumonic pleurisy. Farmacia 64: 946-952, 2016.

12. Tong SY, Davis JS, Eichenberger E, Holland TL and Fowler VG Jr: Staphylococcus aureus infections: Epidemiology, pathophysiology, clinical manifestations, and management. Clin Microbiol Rev 28: 603-661, 2015.

13. Cahill TJ and Prendergast BD: Infective endocarditis. Lancet 387: 882-893, 2016.

14. Tănase A, Coliță A, Ianoşi G, Neagoe D, Brănişteanu DE, Călina D, Docea AO, Tsatsakis A and Ianoşi SL: Rare case of disseminated fusariosis in a young patient with graft vs. host disease following an allogeneic transplant. Exp Ther Med 12: 2078-2082, 2016.

15. Kamal AM, Mitrut P, Docea AO, Soşoi S, Kamal KC, Mitrut R, Mărgăritescu D, Calina D, Banciu C, Tica OS, et al: Double therapy with pegylated Interferon and Ribavirin for chronic hepatitis C. A pharmacogenenetic guide for predicting adverde events. Farmacia 65: 877-884, 2017.

16. Sader HS, Jones RN, Gales AC, Silva JB, Pignatari AC and Group SP; SENTRY Participants Group (Latin America): SENTRY antimicrobial surveillance program report: Latin American and Brazilian results for 1997 through 2001. Braz J Infect Dis 8: 25-79, 2004.

17. Sahoo KC, Tamhankar AJ, Sahoo S, Sahu PS, Klintz SR and Lundborg CS: Geographical variation in antibiotic-resistant Escherichia coli isolates from stool, cow-dung and drinking water. Int J Environ Res Public Health 9: 746-759, 2012.

18. Central Laboratory Standards Institute: Performance standards for antimicrobial susceptibility testing; eighteenth informational supplement. CLSI document M100-18: Wayne, PA, 2008.

19. Bonferroni CE: Teoria statistica delle classi e calcolo delle probabilità. Pubblicazioni del R Istituto Superiore di Scienze Economiche e Commerciali di Firenze. Vol. 8. pp3-62, 1936.

20. Ungureanu A, Zlatian O, Mitroi G, Drocas A, Tîrcă T, Călina D, Dehelean C, Docea AO, Izotov BN, Rakitskii VN, et al: Staphylococcus aureus colonisation in patients from a primary regional hospital. Mol Med Rep 16: 8771-8780, 2017.

21. Weisman LE: Coagulase-negative staphylococcal disease: Emerging therapies for the neonatal and pediatric patient. Curr Opin Infect Dis 17: 237-241, 2004.

22. da Silva AR, Simões ML, Werneck LS and Teixeira $\mathrm{CH}$ : Healthcare associated infections caused by coagulase-negative Staphylococci in a neonatal intensive care unit. Rev Bras Ter Intensiva 25: 239-244, 2013.

23. Macharashvili N, Kourbatova E, Butsashvili M, Tsertsvadze T, McNutt LA and Leonard MK: Etiology of neonatal blood stream infections in Tbilisi, Republic of Georgia. Int J Infect Dis 13: 499-505, 2009.

24. Frimodt-Møller N, Espersen F, Skinhøj P and Rosdahl VT: Epidemiology of Staphylococcus aureus bacteremia in Denmark from 1957 to 1990. Clin Microbiol Infect 3: 297-305, 1997.

25. Uhlemann AC, Otto M, Lowy FD and DeLeo FR: Evolution of community - and healthcare-associated methicillin-resistant Staphylococcus aureus. Infect Genet Evol 21: 563-574, 2014.

26. Lee JH and Kim YH: Predictive factors of true bacteremia and the clinical utility of blood cultures as a prognostic tool in patients with community-onset pneumonia. Medicine (Baltimore) 95: e5058, 2016.

27. McCulloh RJ, Koster MP, Yin DE, Milner TL, Ralston SL, Hill VL, Alverson BK and Biondi EA: Evaluating the use of blood cultures in the management of children hospitalized for community-acquired pneumonia. PLoS One 10: e0117462, 2015.

This work is licensed under a Creative Commons Attribution-NonCommercial-NoDerivatives 4.0 International (CC BY-NC-ND 4.0) License. 